called upon, in a paper submitted to the Australian Journal of Physics in reply to another critic.

But in truth such calculations are not needed. In Dr. Crawford's experiments a traveller with the mesons would find that the life of eerthbound particles was abnormally long, just as each of two approaching observers ascribes the same Doppler effect to the other. If this were not so, we would have an absolute criterion of which was moving. Such a traveller could therefore apply Dr. Crawford's argument to obtain the opposite of Dr. Crawford's result. This alone shows that that result cannot be right.

In a variety of incompatible arguments for this asymmetrical ageing there is, I think, one common feature, namely, a confusion of co-ordinate times with observed times. Only the 'traveller' (whichever he may be) is present at all stages of the journey; his time (namely, $2 t_{2}{ }^{\prime}$ ) is therefore wholly observed. The 'stay-at-home' observes both beginning and end, and his times for these must agree with the 'traveller's' ; but when the 'traveller' is at a distance the 'stay-athome' can give only a co-ordinate time. This, as everybody realizes, differs from the 'traveller's' observed time; but it is a gross error to regard this difference as having any absolute observable significance. It might help to avoid further digressions if I say that I freely assent to the so-called 'relativistic contraction of time'; I have never thought of questioning it. What I deny is the asymmetry. If Einstein's theory is right-and I do not doubt it-the 'traveller' will come back younger than he expected to $b \theta$, but all that his twin (if he is not a relativist) will dispute is the 'traveller's' tale that he has been so far as he says : their best friend will still not know them apart. I hope this statement will discourage further attempts to 'prove' the asymmetry by experiments or calculations which show only that the duration of the 'traveller's' journey differs from the pre-relativity expectation.

It should be obvious that if there is an absolute effect which is a function of velocity only, then the velocity must be absolute. No manipulation of formulæ or devising of ingenious experiments can alter that simple fact.

Purley, Surrey.

Herbert Dingle

${ }^{2}$ Bull. Inst. Phys., 7, 314 (1956).

${ }^{2}$ Proc. Phys. Soc. Lond., A, 69, 925 (1956).

Nature, 178, 680 (1956).

\section{Rock Magnetism}

DR. J. A. CLEGG's account ${ }^{1}$ of the discussion on "Rock Magnetism" at the British Association meeting makes reference to comparisons between the palæomagnetic measurements on rock series in Great Britain and the United States, and seeks to show that a comparison of the pole positions deduced for the Triassic of Great Britain by himself and colleagues ${ }^{2}$ and from Dr. J. W. Graham's measurements ${ }^{3}$ on the Permian sandstones of the United States "suggest that there may also have been a relative movement between Britgin and North America . . .". Although he qualifies this statement, it still appears to me to be misleading, because if one only had this comparison, one would not be led to any suggestion of the possibility of continental drift in the North Atlantic basin. The duration of the Permian and Triassic together is of the order of 70 million years ${ }^{4}$, and the geological time correlation of the red beds used in this palæomagnetic work can only be good to about half a geological period. Creer, Irving and Runcorn ${ }^{5}$ have shown that polar wandering takes place through geological time at about one-third of a degree per million years on the average, so that a motion of the pole of about $20^{\circ}$ could possibly have occurred between the times represented by the rocks examined by Clegg et al. in England and those of Graham in the United States.

It is, of course, only because of results from British $^{5}$ and American ${ }^{6}$ strata of several geological ages, to which Dr. Clegg does not refer, that the possibility of continental displacement between Great Britain and North America must now be seriously entertained. It has been shown ${ }^{7,8}$ for five geological periods, ranging in age from the late PreCambrian to the Triassic, that the poles deduced from American rocks are systematically west (by about the same amount) of the poles deduced from British rocks of corresponding geological age. The comparison of Graham's and Clegg's measurements alone are of no relevance to the problem of continental drift.

The claim made by Prof. P. M. S. Blackett at this meeting and on other occasions ${ }^{9}$ that Dr. Clegg and his colleagues obtained "the first palæomagnetic evidence of past continental land movement ..." is not correct-see references 5 and 10 , for example.

It is to be regretted that Dr. Clegg's discussion of the measurements at Imperial College of the Deccan Trap series of India and of the Tasmanian Dolerites does not discuss lrving's determinations ${ }^{7,11}$ of the directions of magnetization of these rock series, the pole positions he deduces from them and his discussions of the significance of the results, an omission which is also characteristic of the more extensive papers ${ }^{12}$ on the same topics which Dr. Clegg and his colleagues have recently published.

Physics Department,

S. K. RUNCORN

\section{King's College,}

Newcastle upon Tyne.

${ }^{1}$ Clegg, J. A., Nature, 178, 1085 (1956).

${ }^{a}$ Clegg, J. A., Almond, M., and Stubbs, P. H. S., Phil. Mag., 45,

${ }^{8}$ Graham, J. W., J. Geophys. Res., 60, 329 (1955).

"Holmes, A., "Principles of Physical Geology" (Nelson and Son, 1949).

'Creer, K. M., Irving, E., and Runcorn, S. K., J. Geomag. Geoelect., 6, 163 (1954); Phil. Trans. (1957).

'Runcorn, S. K., Nature, 176, 505 (1955); Bull. Geol. Soc. Amer., 67, 301 (1956).

7 Irving, E., Geofisica Pura et App., 33, 23 (1956).

8 Runcorn, S. K., Proc. Canad. Assoc. Geol., 8, 77 (1956).

- Blackett, P. M. S., Listener, 52, 1112 (1954); "Lectures on Rock Magnetism", p. 34 (Weizmann Science Press, Jerusalem, 1956); Royal Institution discourse, Proc. in the press)

${ }^{10}$ Report on meeting by Griffths, D. H., and King, R. F., Nature, $173,1114(1954)$

${ }^{11}$ Irving, E., Ph.D. thesis, Cambridge (1954); Papers and Proc. Roy. Soc. Tasmania, 90, 157 (1956).

19 Clegg, J. A., Deutsch, E. R., and Griffiths, D. H., Phit. Mag., Ser. 8, Mag., Ser. 8, 1, 771 (1956).

\section{Durations of After-hyperpolarization of Motoneurones supplying Fast and Slow
Muscles}

WHEN an impulse invades the soma and dendrites of a mammalian motoneurone, the spike potential is always followed by a phase of increased membrane potential, that is, by a hyperpolarization, which has hitherto been referred to as the positive after-potential $^{1}$. Since these responses are now investigated by 